\title{
O DIREITO AO MEIO AMBIENTE DO TRABALHO EQUILIBRADO E SEM DISCRIMINAÇÃO: UM DIREITO FUNDAMENTAL NA CONSTITUIÇÃO BRASILEIRA DE 1988
}

\section{THE RIGHT TO A DECENT WORK ENVIRONMENT WITHOUT DISCRIMINATION: A FUNDAMENTAL RIGHT IN THE 1988 BRAZILIAN CONSTITUTION}

\author{
Graciane Rafisa Saliba*
}

\begin{abstract}
Resumo: O meio ambiente delineado na Constituição da República Federativa do Brasil de 1988, numa interpretação holística, engloba inclusive a seara laboral. A observância às normas de saúde, segurança e higiene são essenciais no ambiente de trabalho, e, também o clima organizacional e a não-discriminação, para propiciar dignidade humana e valorização do trabalhador, direitos humanos alçados a tratamento constitucional. Busca-se a prevenção de incidentes e infortúnios, assim como o combate à discriminação, com a responsabilização do empregador, subjetivamente ou objetivamente, quando há desrespeito às normas, com o cunho de desincentivar a inadimplência e a inobservância de uma conduta prol, tanto do empregador quanto dos trabalhadores. O respeito e o zelo com o ambiente e com o outro, especialmente no âmbito de trabalho vai ao encontro da função social da propriedade, prevista no artigo 170 da Constituição Brasileira de 1988, bem como cumpre os requisitos do artigo 225 e artigo $5^{\circ}$, XLI, do mesmo instrumento, configurados, portanto, como direito fundamental. Para abordagem do tema foi utilizada revisão bibliográfica, com pesquisa exploratória e explicativa, com utilização de método dedutivo, partindo-se de conhecimentos gerais e preestabelecidos que conduziram à necessidade de não-discriminação no meio ambiente de trabalho para alcance da dignidade humana.
\end{abstract}

Palavras-chave: Meio ambiente do trabalho. Direitos humanos. Direito fundamental. Não-discriminação.

Abstract: The environment outlined in the Constitution of the Federative Republic of Brazil made in 1988, in a holistic interpretation, encompasses even the labor sector. Compliance with health, safety and hygiene standards are essential in the work environment, and also the organizational climate and non-discrimination, promoting human dignity and valorization of the worker are considered human rights, raised to

\footnotetext{
* Doutorado em Direito Privado/Direito do Trabalho e Mestrado em Direito Público pela Pontifícia Universidade Católica de Minas Gerais. MBA em Direito do Trabalho pela Fundação Getúlio Vargas (FGV), com extensão pela Ohio University, Estados Unidos. Doutorado em Direito Privado/Direito do Trabalho e Mestrado em Direito Público pela Pontifícia Universidade Católica de Minas Gerais. MBA em Direito do Trabalho pela Fundação Getúlio Vargas (FGV), com extensão pela Ohio University, Estados Unidos.
} 
constitutional treatment. It seeks to prevent incidents and misfortunes, as well as the fight against discrimination, subjectively or objectively, when there is a disrespect to the rules, with the aim of discouraging the non-observance by employers or workers. The respect and care for the environment and the people, especially in the field of work, is in keeping with the social function of property, provided by article 170 of the 1988 Brazilian Constitution, as well as fulfills the requirements of articles 225 and 5, $\mathrm{XLI}$ of the same instrument, which are therefore a fundamental right. In order to approach the theme, a bibliographical review was used, with exploratory and explanatory research, using a deductive method, based on general and preestablished knowledge that led to the need for non-discrimination in the work environment to achieve human dignity.

Keywords: Work environment. Human rights. Fundamental right. Non-discrimination 


\section{CONSIDERAÇÕES INICIAIS}

A construção de um meio ambiente equilibrado requer a observância de normas de saúde, segurança, higiene, e, ainda, um clima propício ao desenvolvimento e convívio social, sem discriminação, ou seja, além dos elementos físicos e biológicos há também a imprescindibilidade de um conteúdo moral, para que não haja ocorrência de qualquer espécie de segregação ou distinção, com violação de preceitos fundamentais de igualdade e dignidade humana.

A interpretação da amplitude do meio ambiente, reconhecendo-o como direitos humanos, com diversas faces e aspectos, advém de declarações internacionais, dentre elas a Declaração Universal dos Direitos Humanos, da Convenção Internacional sobre a Eliminação de todas as formas de discriminação racial, adotada pela Resolução n. 2106-A da Assembleia das Nações Unidas, em 21 de dezembro de 1965, e ratificada pelo Brasil em 27 de março de 1968; a Convenção sobre a eliminação de todas as formas de discriminação contra a mulher, adotada e aberta à assinatura, ratificação e adesão pela Resolução 34/180, da Assembleia Geral das Nações Unidas, de 18 de dezembro de 1979, ratificada pelo Brasil em 2002, com o Decreto n. 4.377, de 13 de setembro de 2002; a Convenção internacional sobre os direitos das pessoas com deficiência e seu protocolo facultativo, assinados em Nova lorque em 30 de março de 2007, e promulgados no Brasil com o decreto n. 6.949, de 24 de agosto de 2009; a Convenção sobre os direitos das pessoas com deficiência e seu protocolo facultativo, ratificados pelo Congresso Nacional por meio do decreto legislativo $n$. 186 , de 9 de julho de 2008, inclusive com os trâmites previstos no parágrafo $3^{\circ}$ do artigo $5^{\circ}$ da Constituição Brasileira de 1988, que aprova com hierarquia de emenda constitucional, e que, posteriormente, culminou na feitura da Lei n. 13.146, de 6 de julho de 2015, conhecida como Estatuto da pessoa com deficiência; além de instrumentos normativos elaborados no seio da Organização Internacional do Trabalho (OIT), tais como a Convenção n. 100, de 1951, que trata sobre a igualdade de remuneração entre homens e mulheres por um trabalho de igual valor; a Convenção n. 111, de 1958, que visa a eliminação da discriminação no acesso ao emprego, nas condições de formação e de trabalho, com fundamento na raça, cor, 
sexo, religião, opinião política, ascendência nacional ou origem social, além de promover a igualdade de oportunidades e de tratamento em matéria de emprego e de profissão, entre outras.

Debate-se, assim, quais são os requisitos para alcance de um meio ambiente laboral equilibrado, quais as normas para que a função social da propriedade, prevista no Art. 170 da Constituição Brasileira de 1988, bem como para a observância de um meio ambiente digno, nos termos do Art. 225 e do Art. $5^{\circ}, \mathrm{XLI}$ do mesmo instrumento, sejam efetivamente respeitados.

É trazido à baila, por meio de uma revisão bibliográfica, com pesquisa exploratória e explicativa, com utilização do método dedutivo, a necessidade de nãodiscriminação no meio ambiente de trabalho e as consequências advindas do desrespeito e infringências dessas normas e condutas no tocante ao empregador, para valorização do trabalhador e preservação da dignidade humana.

\section{MEIO AMBIENTE DO TRABALHO: DIREITO FUNDAMENTAL}

Os direitos humanos são moldados no decorrer dos anos, reflexo de uma longa e dialética trajetória, trazidos muitas vezes como uma resposta às necessidades sociais, com novas exigências decorrentes dessas relações e das condições históricas e culturais. Essa formação, com o estabelecimento de normas que possibilitam a convivência em sociedade já era vivenciado desde o Código de Hamurabi (1690 a.C.), cuja codificação consagrou, na antiguidade, um rol de direitos comuns a todos os homens (MORAES, 2007, p. 6). Posteriormente verifica-se também a contribuição dos gregos para a formação do pensamento filosófico e jusfilosófico, assim como os romanos que também exerceram papel relevante, ao elaborarem um mecanismo visando a proteção dos direitos individuais (MAGALHÃES, 2002, p. 24).

Já em 1789 a grande inovação foi dada pela Declaração dos Direitos do Homem e do Cidadão, ao tratar de princípios norteadores de igualdade, liberdade e fraternidade. E, a partir daí, diversas Declarações passaram a tratar do tema, tal como a Declaração de Direitos dos Estados Unidos e também a da Revolução 
Francesa, que destacou o direito à vida, à liberdade, à propriedade, à segurança e à igualdade.

Normas reconhecidas como direitos humanos, que passaram a ser inseridos em instrumentos internos dos Estados, com apreço nas ordens jurídico-institucionais nacionais, o que levou a serem chamados por alguns doutrinadores de direitos fundamentais, como explicitado por Ingo Sarlet:

[...] em que pese sejam ambos os termos ("direitos humanos" e "direitos fundamentais") comumente utilizados como sinônimos, a explicação corriqueira e, diga-se de passagem, procedente para a distinção é de que o termo "direitos fundamentais" se aplica para aqueles direitos do ser humano reconhecidos e positivados na esfera do direito constitucional positivo de determinado Estado, ao passo que a expressão "direitos humanos" guardaria relação com os documentos de direito internacional, por referir-se àquelas posições jurídicas que se reconhecem ao ser humano como tal, independentemente de sua vinculação com determinada ordem constitucional, e que, portanto, aspiram à validade universal, para todos os povos e tempos, de tal sorte que revelam um inequívoco caráter supranacional (internacional)" (SARLET, 2009, p. 29).

O reconhecimento e o tratamento constitucional foi sendo estendido, alcançando inclusive os direitos difusos, dentre eles os direitos ambientais, como o meio ambiente do trabalho.

A efetividade dos direitos humanos requer uma sincronicidade entre vários deles, como o direito à vida, à saúde e ao meio ambiente saudável e equilibrado, já que não se pode viver dignamente sem que as condições sejam propícias, e somente quando atendidas tais condições poderão ser exercitados os demais direitos humanos, dentre eles os sociais e os políticos.

A priorização da produção, num primeiro momento no cenário histórico, relegou a segundo plano a questão ambiental, diante da necessidade de desenvolvimento e progresso:

Em seu início, o século $X X$ tinha herdado dos séculos anteriores, em especial do final do século XIX, a ideia de que o desenvolvimento material das sociedades, tal como potencializado pela Revolução Industrial, era o valor supremo a ser almejado, sem contudo atentarse para o fato de que as atividades industriais têm um subproduto altamente nocivo para a natureza e, em consequência, para o próprio homem. Na verdade, inexistia mesmo uma preocupação com o meio 
ambiente que cercava as indústrias, pois, à falta de problemas agudos, havia um entendimento generalizado de que a natureza (entendida como um "dado" exterior ao homem) seria capaz de absorver materiais tóxicos lançados ao meio ambiente, e, por um mecanismo "natural" (talvez "mágico"?!), o equilíbrio seria mantido de maneira automática (SOARES, 2001, p. 35).

Os acúmulos degradativos do meio ambiente, com desenvolvimento desenfreado e inconsequente, incidiram na saúde da população e também dos trabalhadores, refletindo em afastamentos, problemas de saúde, acidentes e levando até a óbitos. Exsurge a necessidade de um desenvolvimento sustentável, com a utilização racional dos bens e fatores de produção naturais, priorização da qualidade de vida e possibilidade de existência digna. Pensamento difundido na esfera mundial, com o tema levado a tratamento na Organização das Nações Unidas (ONU), que convocou a Conferência de Estocolmo, em 1972, especialmente dedicada ao meio ambiente humano, e que resultou na instituição do Programa das Nações Unidas para o Meio Ambiente - Pnuma.

Os Estados passaram, então, a inserir o direito ao meio ambiente em instrumentos constitucionais, explicitando o tratamento de direito fundamental, como foi o caso do Brasil, no Art. 225 da CF/88, ao expressar que "todos têm direito ao meio ambiente ecologicamente equilibrado, bem de uso comum do povo e essencial à sadia qualidade de vida, impondo-se ao Poder Público e à coletividade o dever de defendê-lo e preservá-lo para as presentes e futuras gerações" (BRASIL, 1988).

A ideia de concomitância dos direitos para alcance da efetividade perpassa e se fortalece, já que a plenitude do direito à vida requer um ambiente saudável e com qualidade, em diversos aspectos e locais, como o ambiente laboral.

Sendo assim, não há como se interpretar o meio ambiente sem correlacionar ao trabalho, as condições dignas laborais que afetam diretamente a dignidade e a vida. Nesse sentido, ao abordar meio ambiente deve ser levado em conta também o laboral, que é dado, então, como direito fundamental inserto nos dizeres do supramencionado Art. 225, CF/88, como explica Sebastião Geraldo de Oliveira:

O meio ambiente do trabalho está inserido no meio ambiente em geral (Art. 200, VIII, da Constituição da República), de modo que é impossível alcançar qualidade de vida sem ter qualidade de trabalho, nem se pode atingir meio ambiente equilibrado e sustentável, 
ignorando o meio ambiente do trabalho. Nessa perspectiva, a Constituição de 1988 estabeleceu expressamente que a ordem econômica deve observar o princípio da defesa do meio ambiente (Art. 170, VI) (OLIVEIRA, 2011, p. 142).

Vislumbra-se, pois uma indivisibilidade dos direitos fundamentais, expressa na própria Constituição de 1988, que corrobora a importância do meio ambiente do trabalho, no artigo 200, inciso VIII da CF/88, ao determinar como competência do sistema único de saúde, a colaboração na proteção do meio ambiente, nele compreendido o do trabalho.

No mesmo sentido a Lei n. 6.938/81, que versa sobre a Política Nacional de Meio Ambiente, inseriu o âmbito laboral dentro do conceito de meio ambiente, para busca de desenvolvimento sócio-econômico com proteção da dignidade da vida humana.

\section{SAÚDE E SEGURANÇA NO MEIO AMBIENTE DO TRABALHO: DIREITO FUNDAMENTAL}

O labor e o ambiente de trabalho são essenciais para o desenvolvimento, em sua plenitude, haja vista que grande parte da vida é dispendida no serviço. Para tanto, a interpretação do Art. 225, CF/88, para um meio ambiente equilibrado e sadio, deve abranger os diversos aspectos e ambientes, dentre eles a seara laboral.

O tema ambiental foi abordado não somente no instrumento constitucional, mas em diversas normas do arcabouço jurídico brasileiro, como na Consolidação das Leis do Trabalho (CLT), de 1943, nos artigos 154 a 201, que determinam condições de saúde e segurança do trabalhador, com normas de utilização de equipamentos de proteção individual, intervalos, exames e registros essenciais que facilitem a fiscalização do Ministério do Trabalho e Emprego.

A observância dessas exigências tem o cunho de proteção do direito à vida, para um meio ambiente adequado, de forma a não gerar infortúnios laborais, acidentes do trabalho ou doenças ocupacionais, que ceifem ou reduzam o direito à vida.

Além dos instrumentos nacionais há também um direcionamento da Organização Internacional do Trabalho (OIT), que tratou de temas que afetam o 
meio ambiente do trabalho, como saúde, higiene e segurança, e favoreceu, assim, a criação de portarias e normas regulamentadoras pelo Ministério do Trabalho, como a Portaria n. 3.214/78.

A Convenção 148 da OIT, ratificada pelo Brasil em 1982, abordou, em seu Art. $4^{\circ}$, a obrigatoriedade de adoção, pela legislação nacional, de medidas no lugar de trabalho para prevenir e limitar os riscos profissionais decorrentes da contaminação atmosférica, ruído e vibrações que puderem ser prejudiciais aos trabalhadores, o que foi posteriormente regulamentado pelo Ministério do Trabalho e Emprego.

A Convenção 152, com normas de segurança e saúde, foi direcionada para uma categoria, a dos trabalhadores portuários, enquanto a de Convenção 167, sobre o mesmo tema, foi criada para os trabalhadores da construção civil, e a de número 176 para os trabalhadores de minas.

$\mathrm{E}$, ainda, outras convenções que tangenciam o meio ambiente do trabalho, elaboradas no seio da OIT, foram ratificadas pelo Brasil, como a de número 161, que trata da instituição de serviço médico para prevenção de doenças profissionais e doenças em geral, e contra os acidentes de trabalho e a Convenção 155, que apresentou diversas normas sobre segurança, higiene e meio-ambiente de trabalho, exigidas para todas as atividades econômicas, e que possibilitou a interrupção de uma situação de trabalho por qualquer trabalhador que considerar, por motivos razoáveis, que envolve um perigo iminente e grave para sua vida ou sua saúde, e, para tanto, Ihe concedeu uma proteção de consequências injustificadas (OIT, 1983), além de prever e promover a adoção de medidas de inclusão das questões de saúde e segurança em todos os níveis de ensino e treinamento, para melhor atendimento e satisfação das necessidades dos trabalhadores.

Ressalta-se, assim, que as normas de proteção e prevenção no tocante à saúde e segurança do trabalho constituem elementos fundamentais para alcance de um meio ambiente do trabalho equilibrado e sadio, propício ao desenvolvimento social e à própria vida, como esboçado na Constituição Brasileira de 1988. 


\section{NÃO-DISCRIMINAÇÃO NO AMBIENTE DE TRABALHO: DIREITO FUNDAMENTAL}

A preconização da igualdade e da dignidade humana, insertas na Constituição da República Federativa do Brasil de 1988, destacadas no Art. $5^{\circ}$, pressupõe uma condição paritária de tratamento, um respeito ao próximo que requer obrigatoriamente a não-discriminação.

A superação de preconceitos possibilita que inúmeras pessoas possam viver em plenitude, com aceitação social, inclusão cidadã e na própria democracia. A discriminação gera uma exclusão, pela condição social, pelo sexo, pela cor, raça, nacionalidade, por doença ou qualquer outra característica, decorrentes da falta de aceitação de diferenças e da intolerância.

Discriminar é excluir, negar cidadania e a própria democracia. Não se
trata de eliminar as diferenças, mas de se obter a igualdade,
identificando as origens da desigualdade, para que a primeira possa
ser garantida a todos. Nos países ricos, atualmente gasta-se o dobro
em publicidade do que se investe em educação. O neoliberalismo
confunde cidadão com consumidor, excluindo aquele que não o for.
O renomado jurista brasileiro, Prof. Dalmo de Abreu Dallari, vê como
raízes subjetivas do preconceito, a ignorância, a educação
domesticadora, a intolerância, o egoísmo e o medo. Para ele, o
preconceito, além de introduzir a discriminação, restringe a liberdade,
acarreta a perda de respeito pela pessoa humana, introduz a
desigualdade e a injustiça (ARNS, 2010, p.17).

Integração entre a liberdade, a dignidade humana e a não discriminação, sendo essencial a coexistência, já que não é possível o alcance de um meio ambiente do trabalho equilibrado sem o respeito e observância de todos esses direitos. A aceitação do outro e daquele que é diferente revela a efetividade da igualdade, que tem respaldo no reconhecimento das especificidades e de um tratamento isonômico conforme as próprias condições desigualitárias.

A conduta discriminatória pode decorrer de um preconceito, com desqualificação de uma pessoa em decorrência de alguma característica que lhe é peculiar, seja pela cor, sexo, opção sexual, raça, situação social, estado civil ou até por ser portador de alguma doença. Há um preconceito, diante de uma ideia ou um conceito sem qualquer fundamento sensato e imparcial, um juízo preconcebido, que 
pode acarretar, então, uma atitude discriminatória perante as pessoas, como salienta Maurício Godinho Delgado:

Discriminação é a conduta pela qual nega-se à pessoa tratamento compatível com o padrão jurídico assentado para a situação concreta, por ela vivenciada. A causa da discriminação reside, muitas vezes, no cru preconceito, isto é, um juízo sedimentado desqualificador de uma pessoa em virtude de uma sua característica, determinada externamente, e identificadora de um grupo ou segmento mais amplo de indivíduos (cor, raça, sexo, nacionalidade, riqueza, etc.) Mas pode, é óbvio, também derivar a discriminação de outros fatores relevantes a um determinado caso concreto específico (DELGADO, 2010, p. 108).

Os mecanismos de proteção contra a ocorrência de discriminação foram incrementados na decorrência da legislação brasileira, se ampliando na medida em que se ampliam as condições democráticas na sociedade, e projetam inclusive na relação de emprego e nos contratos de trabalho.

O preconceito racial advém da crença de que algumas raças humanas são distintas e superiores às outras, enquanto o preconceito social se baseia na equivocada atitude sob o fundamento de que classes mais abastadas são superiores por possuírem bens. Já a discriminação por preconceito quanto a orientação sexual, que procura excluir um grupo de pessoas por sua opção pessoal e sexual, negando sua dignidade, e, inclusive constitui crime de violação de direitos humanos. E há, ainda, o preconceito pela religião, decorrente de intolerância por outra religião que não a sua, e contra deficientes, vislumbrando-os como pessoas com incapacidade e limitações, e rejeitando, injustamente, pela condição de vulnerabilidade que podem, muitas vezes se encontrar, da mesma forma pessoas que apresentam doenças graves que também são excluídas do convívio social e muitas vezes do próprio ambiente de trabalho.

Há, pois, que ter como vetor, num Estado Democrático de Direito, a igualdade de todos, sem distinção de qualquer natureza, com a inviolabilidade do direito à vida, à liberdade, à igualdade, à segurança e à propriedade, conforme expresso no Art. $5^{\circ}$ da Constituição Brasileira.

Como reflexo desses direitos, a Lei 9029/95, no Art. $1^{\circ}$, com redação dada pela Lei 13.146/2015, proíbe a adoção de qualquer prática discriminatória e limitativa 
para efeito de acesso à relação de trabalho, ou de sua manutenção, por motivo de sexo, origem, raça, cor, estado civil, situação familiar, reabilitação profissional, idade, além de vedar qualquer conduta discriminatória no ambiente laboral.

Ressalta-se, pois, que a vedação da discriminação é essencial para alcance de um meio ambiente do trabalho digno e sadio, no qual a igualdade de tratamento $\mathrm{e}$ condições o tornam propícios ao desenvolvimento social e à convivência. E, para tanto, assim como normas de saúde e segurança, a vedação às práticas discriminatórias deve ser fiscalizada permanentemente pelo empregador, desde a seleção até a saída do trabalhador.

\section{RESPONSABILIZAÇÃO POR DESRESPEITO AO MEIO AMBIENTE DO TRABALHO}

A manutenção do sistema capitalista no Brasil é inerente à busca de lucro pelos proprietários dos fatores de produção, o que não constitui demérito, mas se depara com limites diante de valores e princípios expressos no instrumento constitucional. Numa ordem democrática social, reflexo de conflitos socioeconômicos eclodidos no século XIX, a Constituição Brasileira de 1988 buscou priorizar a dignidade da existência da pessoa humana, e, para tanto, se faz essencial a harmonização do capital com o trabalho.

Houve uma preocupação com o social e o coletivo, dada a problemática que poderia advir quando o enfoque fica exclusivamente no indivíduo. $\mathrm{E}$, dessa forma, no título VII da CF/88, da ordem econômica e financeira, valores e princípios sociais foram expressos com uma função limitadora do individualismo, dando "duplo sentido à expressão ordem econômica, ora entendendo-a, numa visão subjetiva" (FIGUEIREDO, 2012, p. 57), como um conjunto de relações econômicas, e ora, objetivamente, "como dever-ser, isto é, como um conjunto de normas jurídicas disciplinadoras dessas relações".

Nesse contexto quatro valores foram insertos no Art. 170 da CF/88, no título VII da ordem econômica e financeira: a valorização do trabalho, a livre iniciativa, a existência digna e a justiça social. Há uma interligação entre eles, não sendo possível falar, por exemplo, em existência digna sem que haja a valorização do 
trabalho humano, e, para tanto faz-se essencial o atendimento das normas de saúde e segurança e o zelo no tocante ao meio ambiente do trabalho.

O artigo 170, CF/88 traz ainda a necessidade de observância da função social da propriedade, como princípio norteador da ordem econômica, para o qual, da mesma forma, o meio ambiente do trabalho e todos os seus aspectos e normas devem ser atentamente cumpridos, com meios propícios para o desenvolvimento social e econômico não só de um indivíduo empregador, mas de uma coletividade. $E$, além disso, a infringência acarreta a responsabilização daquele que tem o dever de fiscalizar o locus laboral, ou seja, o empregador. Diante de tal situação, recomenda-lhes o dever de tomar todas as cautelas, de modo a constituir-lhe um ambiente laboral íntegro e seguro.

O direito à vida e à dignidade, cuja inviolabilidade é assegurada constitucionalmente, é imanente à condição humana e, como tal, é tutelado pelo Estado. Mas, essa responsabilidade também é atribuída aos empregadores relativamente a seus empregados, que assim deverão oferecer meios para a sua proteção, propiciando aos trabalhadores.

Decorre daí o dever de reparar os danos nas hipóteses de agravo resultante de inobservância das normas de saúde e segurança e também da ocorrência de práticas discriminatórias que tornem o ambiente insalubre ou doentio, em virtude da responsabilidade civil do tomador de serviços.

Sendo incontestável o cabimento do reparo à vítima, nas hipóteses de dolo ou culpa do empregador, torna-se essencial perquirir, ainda que de modo sintético, o instituto jurídico da responsabilidade civil.

Maria Helena Diniz (2007, p. 35) afirma que "a responsabilidade civil é a aplicação de medidas que obriguem uma pessoa a reparar dano moral ou patrimonial causado a terceiros, em razão de ato por ela mesma praticado, por uma pessoa por que ela responde, por alguma coisa a ela pertencente ou por simples imposição legal”.

Luciano Ricardo Cembranel (2014, p. 178) afirma que o princípio da responsabilidade civil respalda-se principalmente na doutrina da culpa ou responsabilidade subjetiva, no sentido de "[...] quem der causa a dano alheio deve repará-lo" (Art. 186 do Código Civil). 
Verifica-se que a obrigação de indenizar pressupõe necessariamente o dano efetivamente experimentado pela vítima, sendo que, na esfera trabalhista, constatase o evento danoso nas hipóteses de infortúnio laboral, doença ocupacional (doenças do trabalho e profissional) e também condutas discriminatórias.

Do ponto de vista da responsabilidade subjetiva a comprovação da culpa, em qualquer grau, no evento danoso é condição sine qua non para gerar o dever de indenizar, isto é, provar a ação ou omissão dolosa ou culposa (conduta ilícita) do empregador causador do dano.

A concepção clássica da teoria da culpa ou responsabilidade subjetiva aborda a possibilidade de indenização se constatado simultaneamente o dano, o nexo causal do evento com o trabalho e culpabilidade do empregador, em conformidade respectivamente com os Arts. 186 e caput do 927 do Código Civil e alicerçado no texto constitucional em seu inciso XXVIII, Art. $7^{\circ}$.

Corrente majoritária vislumbra a responsabilização subjetiva, mas, diante das dificuldades probatórias das vítimas, mas é imprescindível uma reflexão acerca da ampliação da responsabilidade do empregador, considerando-se, a priori, que é imperioso propiciar mecanismos que possam atingir a proteção máxima aos trabalhadores, com a prática de normas que efetivamente concretizem um ambiente laboral saudável e seguro, propiciando o merecido respeito em relação à saúde a integridade do trabalhador.

\section{CONCLUSÃO}

O equilíbrio do meio ambiente requer uma conjugação concomitante da ocorrência de diversos direitos, do direito à vida à dignidade humana. $E$, ao interpretar o meio ambiente incluindo o âmbito laboral, acrescenta-se a necessidade de observância das normas de saúde, segurança e também a vedação das condutas discriminatórias, o que torna o ambiente degenerativo e poluído.

A partir da previsão constitucional, que torna o direito ao meio ambiente não apenas parte dos direitos humanos, mas direito fundamental, observa-se uma interpretação extensiva e holística, colocando o indivíduo como cerne do arcabouço jurídico. É necessário interpretar o artigo 225 da Constituição Brasileira de 1988, que 
prevê o direito ao meio ambiente equilibrado, essencial à sadia qualidade de vida para presentes e futuras gerações, conjuntamente com o artigo 200, VIII, CF/88, que coloca o meio ambiente do trabalho como parte do meio ambiente, para, assim, ratificar a necessidade de um local laboral que propicie um desenvolvimento social e psíquico, com observância dos aspectos de saúde, segurança e não discriminação.

Salienta-se, ainda, que as formas de manifestação da discriminação são várias, mas prejudiciais quando baseadas em preconceito que vise excluir socialmente determinada pessoa por pertencer a uma classe ou categoria, ou simplesmente por apresentar determinada característica. E, no ambiente de trabalho diversas causas, infundadamente, levam à diferenciação, desde uma despedida arbitrária por motivo de doença ou até por gravidez, ou o tratamento de desprezo muitas vezes concedido pelo empregador ao empregado por motivo de deficiência, cor, opção sexual, estado civil ou simplesmente por ser mulher.

O combate a essas situações e à infringência de normas de saúde e segurança devem ser intensos, pois a ocorrência viola direito fundamental, o direito ao meio ambiente equilibrado e saudável, acarretando, então, a responsabilização do empregador quando sucedida em ambiente laboral, podendo ser uma responsabilização subjetiva ou até mesmo, para caráter inibitória de práticas lesivas ao meio ambiente, e, consequentemente, à valorização do trabalhador.

Assim, pugna-se pela dignidade e direito à vida, com proteção do meio ambiente laboral, para atendimento da função social da propriedade, sendo que a inobservância pode trazer repercussões para toda a sociedade e não somente para o indivíduo, sendo elas sociais, psicológicas, trabalhistas e previdenciárias.

E, por fim, ressalta-se que os direitos fundamentais são indivisíveis, o que impossibilita que se concretize, isoladamente, um deles, sem que se considere um todo, e a dignidade humana representa o corolário do cumprimento e concomitância de todos.

\section{REFERÊNCIAS}

ARNS, Cardeal Dom Paulo Evaristo. Para que todos tenham vida. In: RENAULT, Luiz Otávio Linhares; VIANA, Márcio Túlio; CANTELLI, Paula Oliveira.

Discriminação. São Paulo: LTr, 2010. 
BRASIL. Constituição (1988). Constituição da República Federativa do Brasil. Disponível em: www.planalto.gov.br/ccivil_03/constituicao/constituicao.htm. Acesso em: 17 ago. 2018.

BRASIL. Lei n. 6.938, de 31 de agosto de 1981. Dispões sobre a política nacional de meio ambiente. Publicada no Diário Oficial da União em 02 set. 1981. Disponível em: http://www.planalto.gov.br/ccivil_03/leis/L6938.htm. Acesso em: 17 ago 2018.

BRASIL. Ministério do Trabalho e Emprego. Estratégia Nacional para Redução dos Acidentes do Trabalho 2015-2016. Disponível em:

http://portal.mte.gov.br/data/files/FF8080814D5270F0014D71FF7438278E/Estrat\%C 3\%A9gia\%20Nacional\%20de \%20Redu\%C3\%A7\%C3\%A30\%20dos\%20Acidentes\% 20do\%20Trabalho\%202015-2016.pdf. Acesso em: 01 ago. 2018.

BRASIL. Tribunal Superior do Trabalho. Empresa é responsabilizada por morte do empregado em acidente de moto. 8 mar. 2013. Disponível em:

<http://www.tst.jus.br/noticias/-/asset_publisher/89Dk/content/id/5257233>. Acesso em: 18 ago. 2018.

CEMBRANEL, Luciano Ricardo. Responsabilidade Civil Objetiva do Empregador pelo Acidente de Trabalho. Caderno da Escola Judicial do TRT da 4a . Região, Porto Alegre, n. 08, 2014.

DELGADO, Maurício Godinho. Proteções contra discriminação na relação de emprego. In: RENAULT, Luiz Otávio Linhares; VIANA, Márcio Túlio; CANTELLI, Paula Oliveira. Discriminação. São Paulo: LTr, 2010. p. 108.

DINIZ, Maria Helena. Curso de direito civil brasileiro. 21. ed. São Paulo: Saraiva, 2007. v. 7.

FIGUEIREDO, Leonardo Vizeu. Lições de direito econômico. 5 ed. Rio de Janeiro: Forense, 2012.

MAGALHÃES, José Luiz Quadros de. Direito constitucional: tomo I. 2 ed. Mandamentos: Belo Horizonte, 2002.

MORAES, Alexandre de. Direitos humanos fundamentais: teoria geral, comentários aos arts. $1^{\circ}$ ao $5^{\circ}$ da Constituição da República Federativa do Brasil, doutrina e jurisprudência. 8 ed. São Paulo: Atlas, 2007.

OLIVEIRA, Sebastião Geraldo. Proteção jurídica à saúde do trabalhador. 5. ed. rev., atual. e ampl. São Paulo: LTr, 2011.

ORGANIZAÇÃO INTERNACIONAL DO TRABALHO (OIT). Convenção sobre contaminação do ar, ruído e vibrações (Convenção 148). 11 jul. 1979. Disponível em <http://www.oitbrasil.org.br/convention>. Acesso em 19 ago. 2018. 
ORGANIZAÇÃO INTERNACIONAL DO TRABALHO (OIT). Convenção sobre segurança e higiene dos trabalhadores portuários (Convenção 152). 05 dez. 1981. Disponível em <http://www.oitbrasil.org.br/convention>. Acesso em 19 ago. 2018.

ORGANIZAÇÃO INTERNACIONAL DO TRABALHO (OIT). Convenção sobre segurança e saúde dos trabalhadores (Convenção 155). 11 ago. 1983. Disponível em < http://www.oitbrasil.org.br/node/504>. Acesso em: 19 ago. 2018.

ORGANIZAÇÃO INTERNACIONAL DO TRABALHO (OIT). Convenção sobre serviços de saúde do trabalho (Convenção 161). 17 fev. 1988. Disponível em <http://www.oitbrasil.org.br/convention>. Acesso em 08 ago. 2018.

ORGANIZAÇÃO INTERNACIONAL DO TRABALHO (OIT). Convenção sobre segurança e saúde na construção civil (Convenção 167). 01 jun. 1988. Disponível em <http://www.oitbrasil.org.br/convention>. Acesso em 09 ago. 2018.

ORGANIZAÇÃO INTERNACIONAL DO TRABALHO (OIT). Convenção sobre segurança e saúde nas minas (Convenção 176). 26 jun. 1995. Disponível em <http://www.oitbrasil.org.br/convention>. Acesso em 09 ago. 2018.

SARLET, Ingo Wolfgang. A eficácia dos Direitos Fundamentais: uma teoria geral dos direitos fundamentais na perspectiva constitucional. 10. ed. Livraria do advogado Editora: Porto Alegre, 2009.

SOARES, Guido Fernando Silva. Direito internacional do meio ambiente: emergência, obrigações e responsabilidade. São Paulo: Atlas, 2001. 